\title{
MMBB arquitectos
}

Angelo Bucci + Milton Braga + Fernando de Mello Franco + Marta Moreira

Viniendo de un país que generó durante el siglo XX un proyecto arquitectónico cargado de una cierta modernidad y teñido por la presencia de Le Corbusier, Niemeyer y la construcción de Brasilia, la neutralidad de la obra de MMBB arquitectos se constituye como una transición hacia el Brasil actual, planteando el silencio como un camino posible.

They emerge from a country whose 20th century architectural project was charged with a certain modernity, marked by the presence of Le Corbusier, Niemeyer and the creation of Brasilia. Today, the neutral nature of the works of MMBB Architects marks a transition, offering silence as a possible route to the new Brazil.

\section{Clínica}

Odontolósica en Orlândia
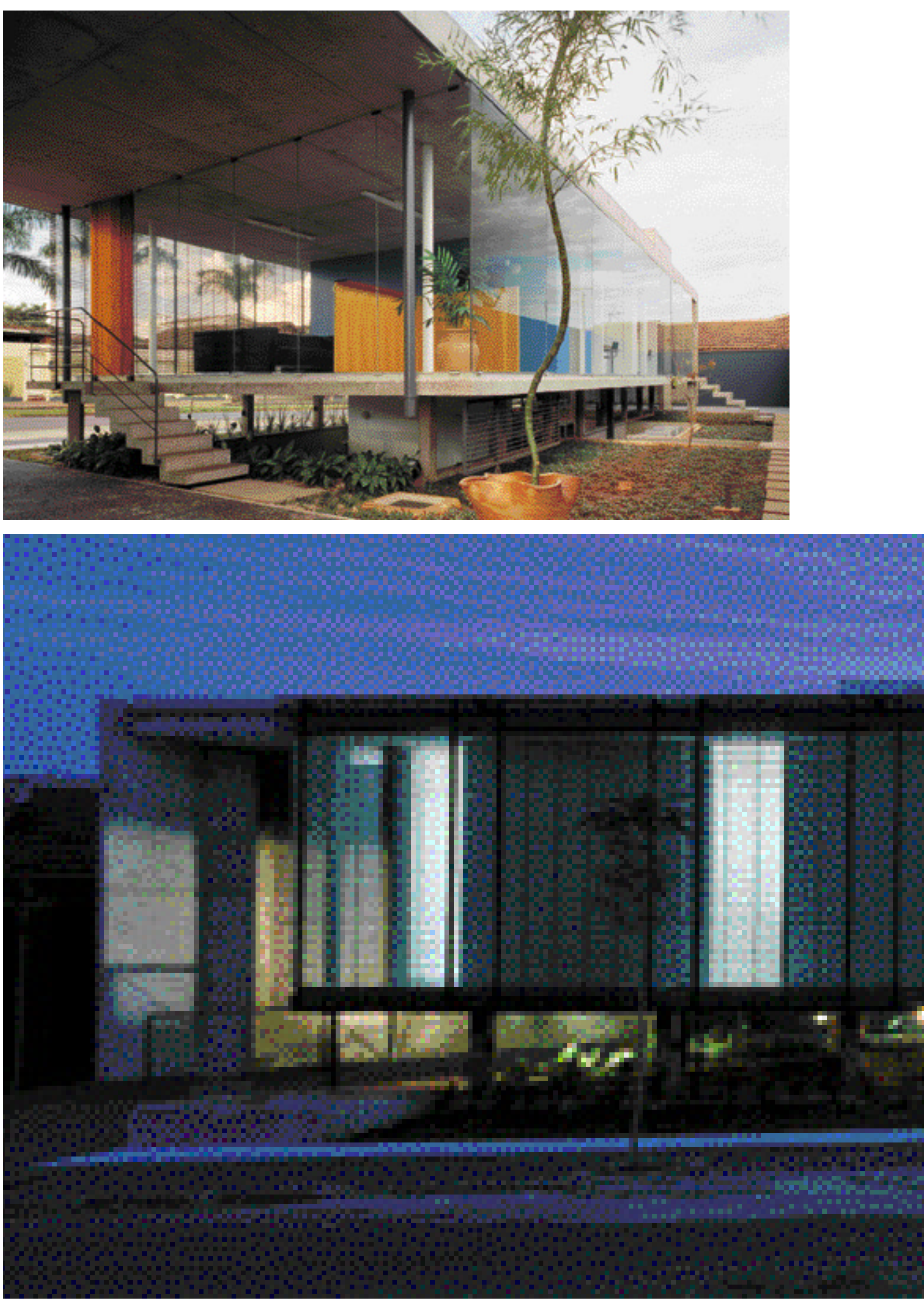


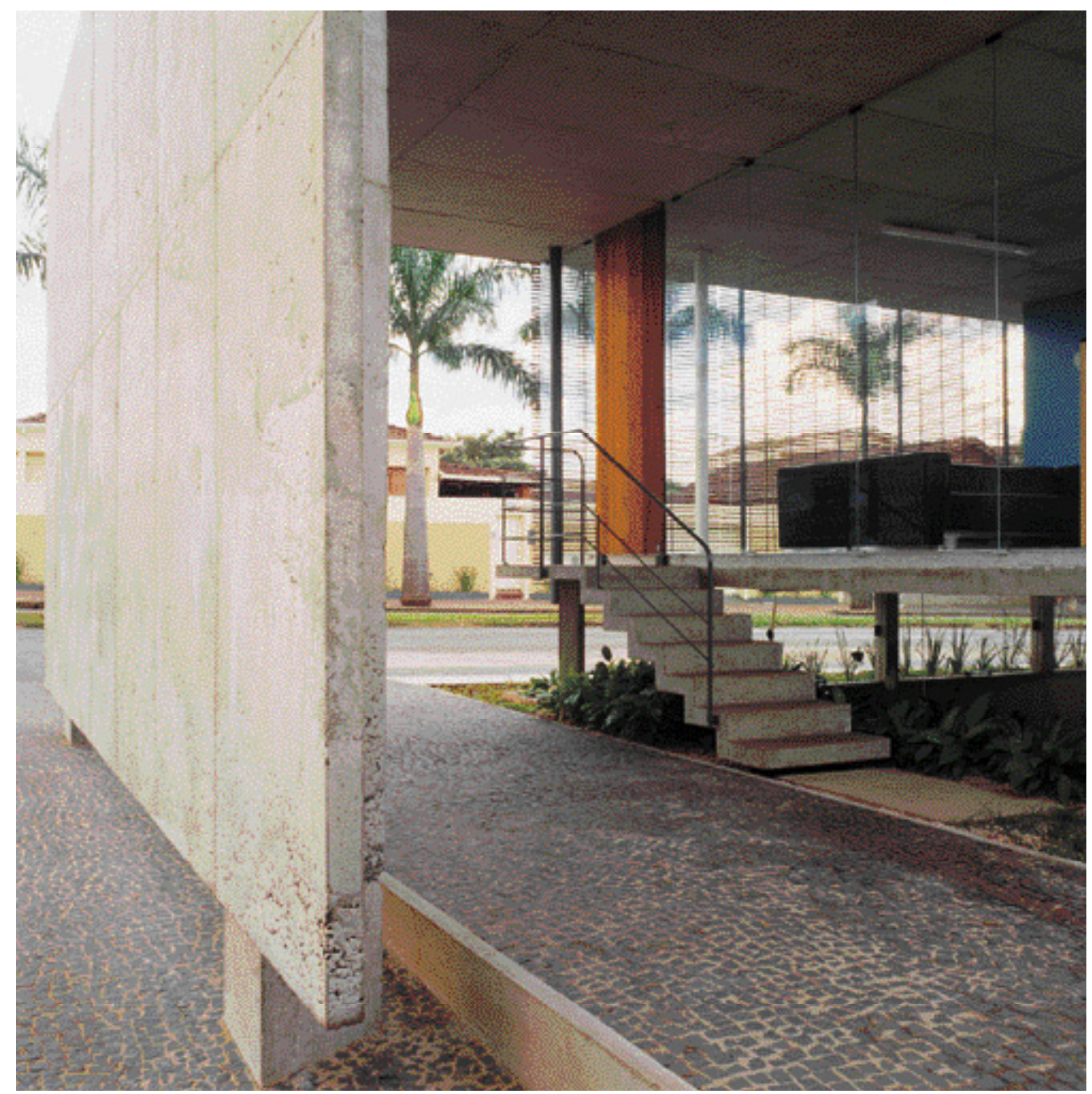

Este edificio, construido en una pequeña ciudad en el interior del Brasil, abriga dos actividades profesionales: odontopediatría y prótesis odontológica, respectivamente clínica y laboratorio.

La implantación del edificio sigue la altura de las casas vecinas, alineándose en los frentes del terreno para las calles. Esto da independencia para la construcción, que es diferente de las otras construcciones del barrio, y al mismo tiempo, refuerza la configuración de la manzana, unidad marcante de la malla ortogonal de calles y avenidas de la ciudad proyectada.

La planta baja fue "duplicada" por desniveles suaves con relación a la calle $-1,25 \mathrm{~m}$ - que conducen a los dos pisos que abrigan, separadamente, la clínica y el laboratorio. Las áreas destinadas al público -clínica- se encuentran en la "planta baja superior". Los ventanales ofrecen una perspectiva de la calle, que hace parte de la memoria de las personas acostumbradas a la diferencia de altura entre el nivel de ésta y el de los pisos interiores debido a la existencia de sótanos elevados, típicos de las primeras casas de la ciudad. Del otro lado, el lado de la ciudad, la transparencia de los vidrios expone sin secretos las actividades de la clínica y del laboratorio como parte de la rutina de las personas.

De esta disposición del programa surgió la simplicidad constructiva del edificio, cuyos pocos y marcantes elementos definen su expresión arquitectónica.

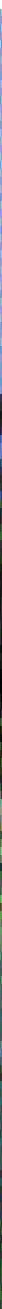



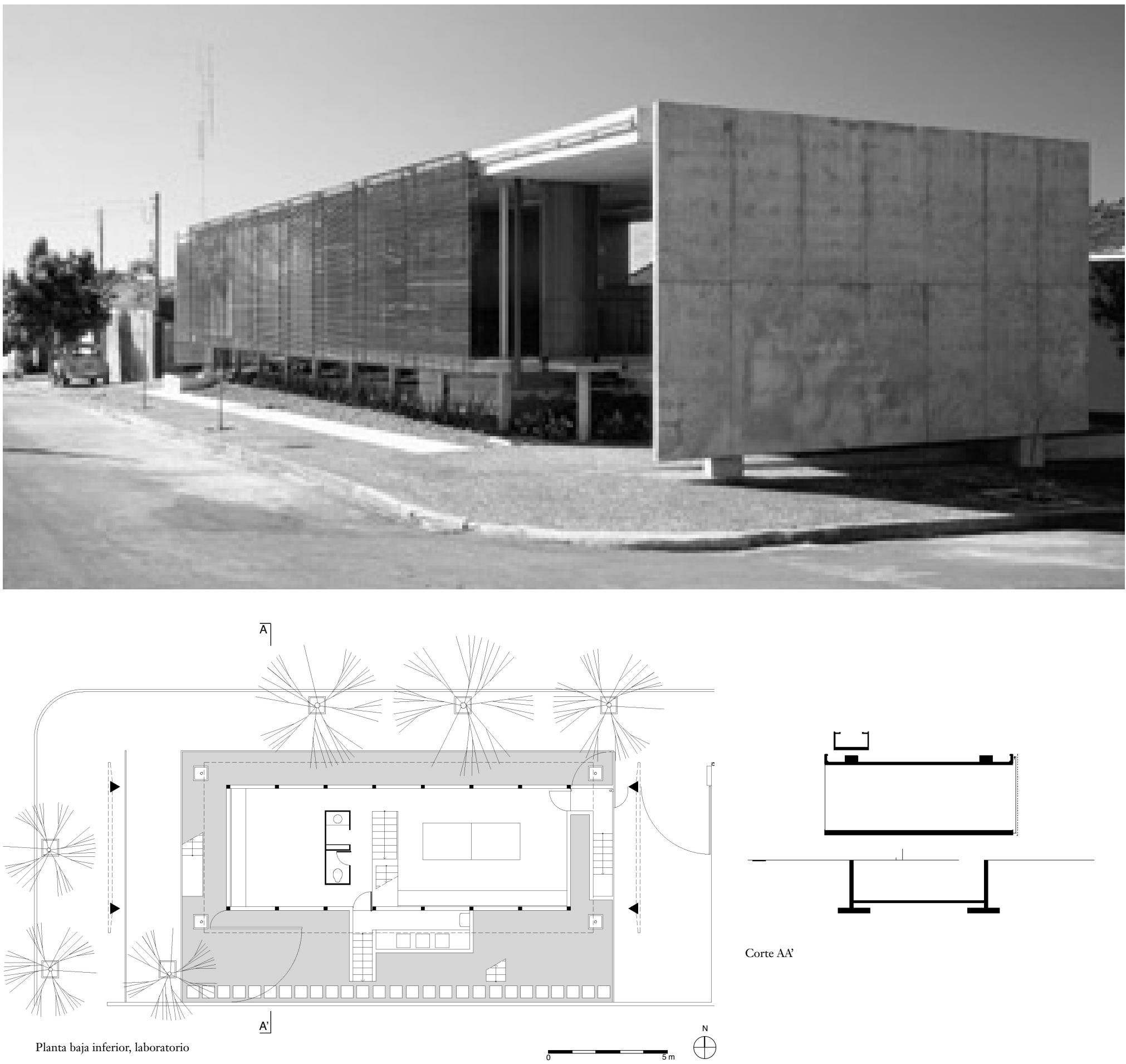

Corte AA'

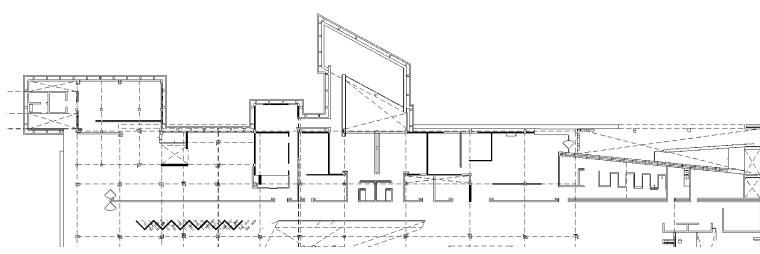

Clínica odontológica en Orlândia

Arquitectos Anselo Bucci, Fernando de Mello Franco, Marta Moreira y Milton Brasa

Colaboradores Keila Costa y Sandra Llovet Vilà

Ubicación Orlândia, Sao Paulo, Brasi

Superficie terreno $250 \mathrm{~m}^{2}$, construida $182 \mathrm{~m}^{2}$

Año proyecto 1998

Finalización de obra 2000 


\section{Casa en la estancia Santa Rita}
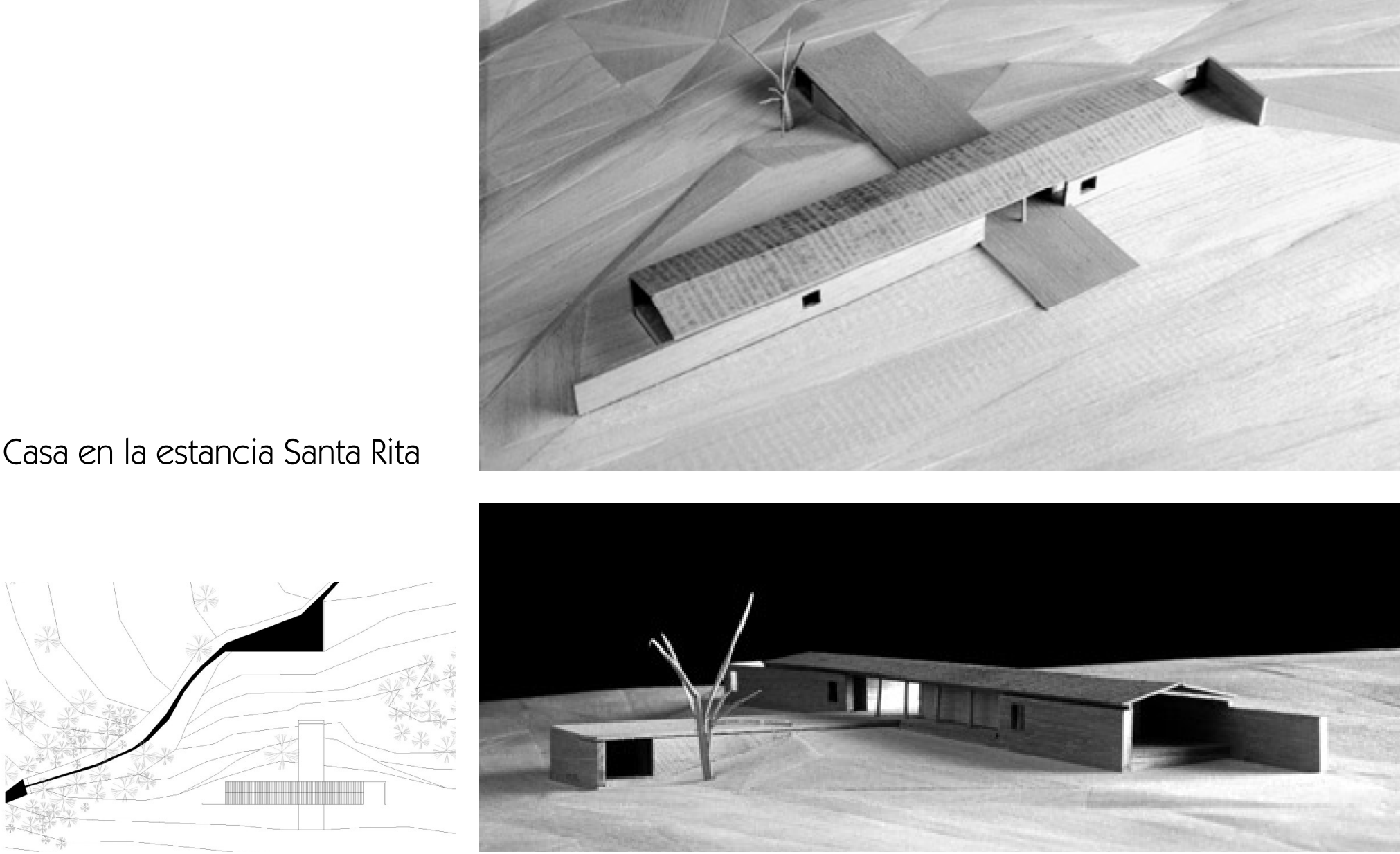

Plano emplazamiento

El proyecto de la casa de la estancia Santa Rita buscó la redefinición del territorio de su implantación. En el lugar, próximo a la sede de la estancia, no se observa ninguna edificación existente, apenas un hermoso paisaje marcado por el trabajo en el campo El proyecto partió del deseo de afirmar con el diseño de la casa la continua reconstrucción de este paisaje. Dos muros de piedra, referencias horizontales de cerca de 50 metros de extensión, fueron seccionados por una plataforma, también de piedra, definiendo el punto de origen del área dominada por la casa. Estos muros soportan un tejado de dos aguas que conforma el espacio cubierto de la casa. Las diversas áreas necesarias para atender el programa flexible de una casa se suceden linealmente en este gran y único pabellón. Dos bloques internos de paredes de albañilería, sueltos de los muros, establecen el límite entre las áreas cerradas y la circulación.

La plataforma es, a su vez, un gran espigón que apunt al horizonte. El proyecto procuró entenderla como un piso insertado en medio de este paisaje $\mathrm{y}$, al mismo tiempo, alejado de él.

Finalmente, un plano inclinado de concreto fue proyectado junto a un riachuelo de estación, espejo de agua en el verano y patio seco en el invierno, marcando, en oposición, la acción de la naturaleza sobre el espacio construido.

\section{Casa en la estancia Santa Rita}

Arquitectos Fernando de Mello Franco,

Marta Moreira y Milton Braga

Colaboradores Alina Arruda D'Alva

y Ana Paula Koury

Ubicación Descalvado, Sao Paulo, Brasil

Superficie cubierta $360 \mathrm{~m}^{2}$, terraza $160 \mathrm{~m}^{2}$

Año proyecto 1995

Fotografía Carlos Kipnis
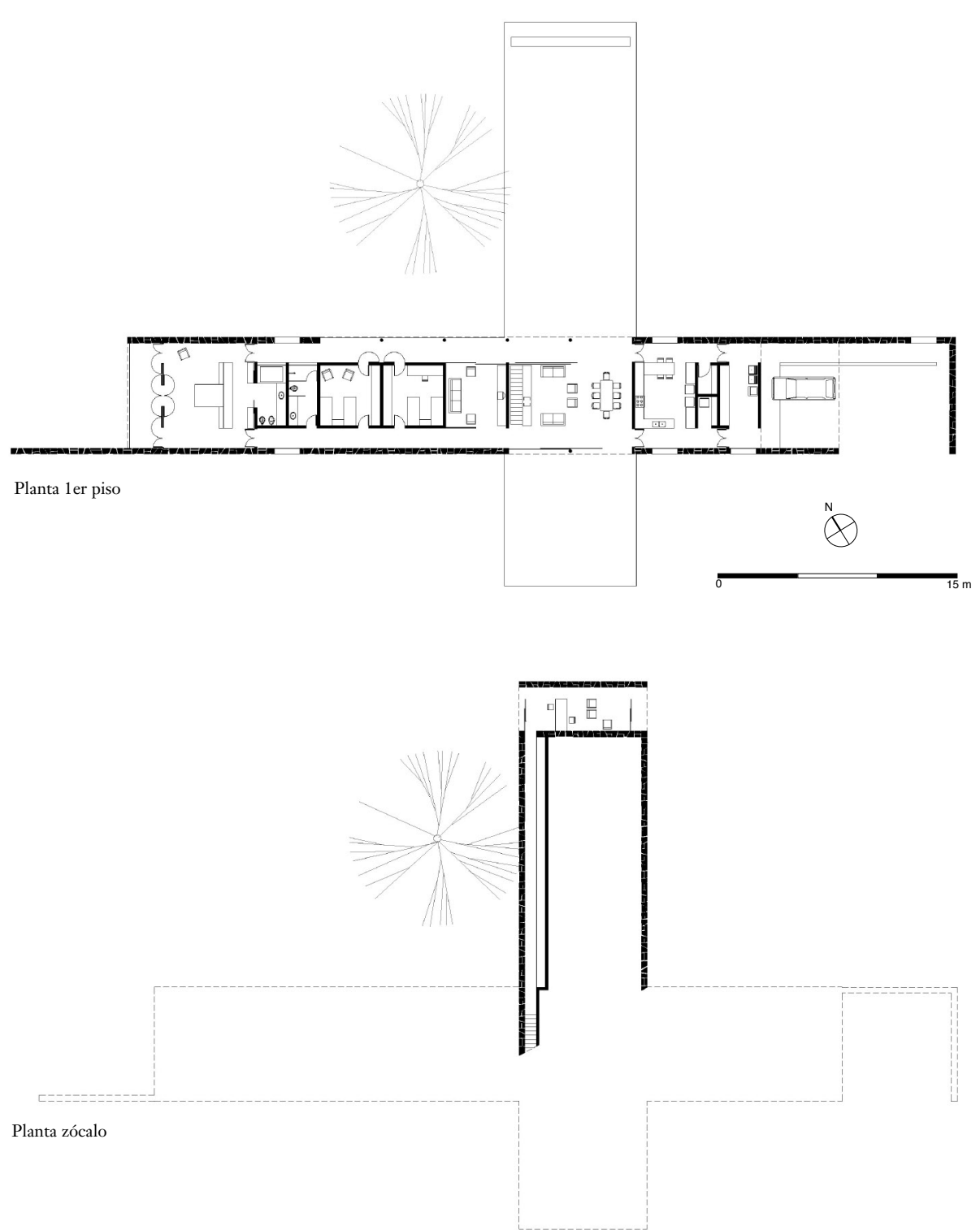


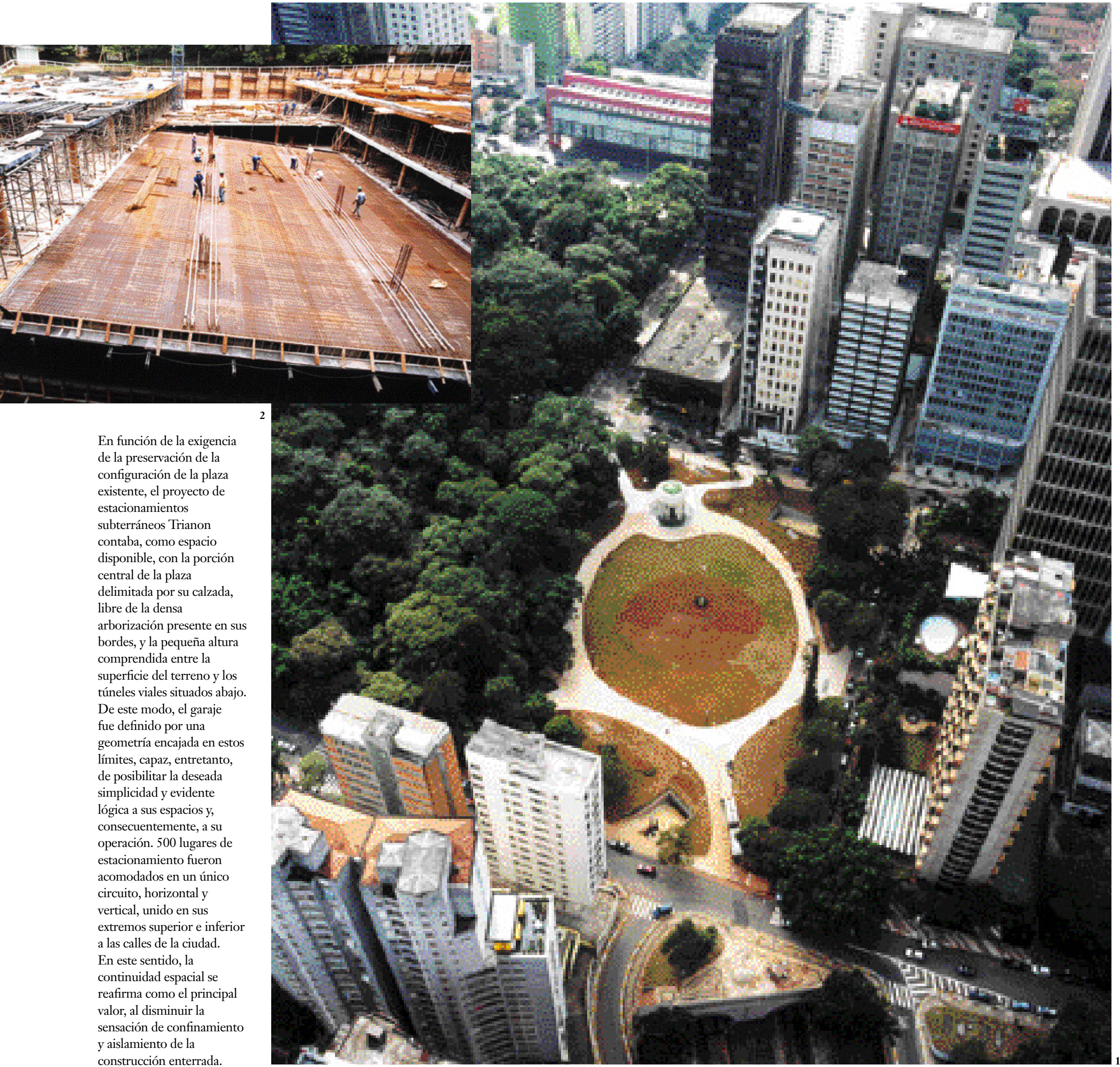

\section{Exerater} thing in 
1 Vista aérea Plaza Trianon.

Arriba, la Avenida Paulista y el

Lin Bo Bardi

2, 3 y 4 Circuito continuo de

planos inclinados, en

construcción y terminados
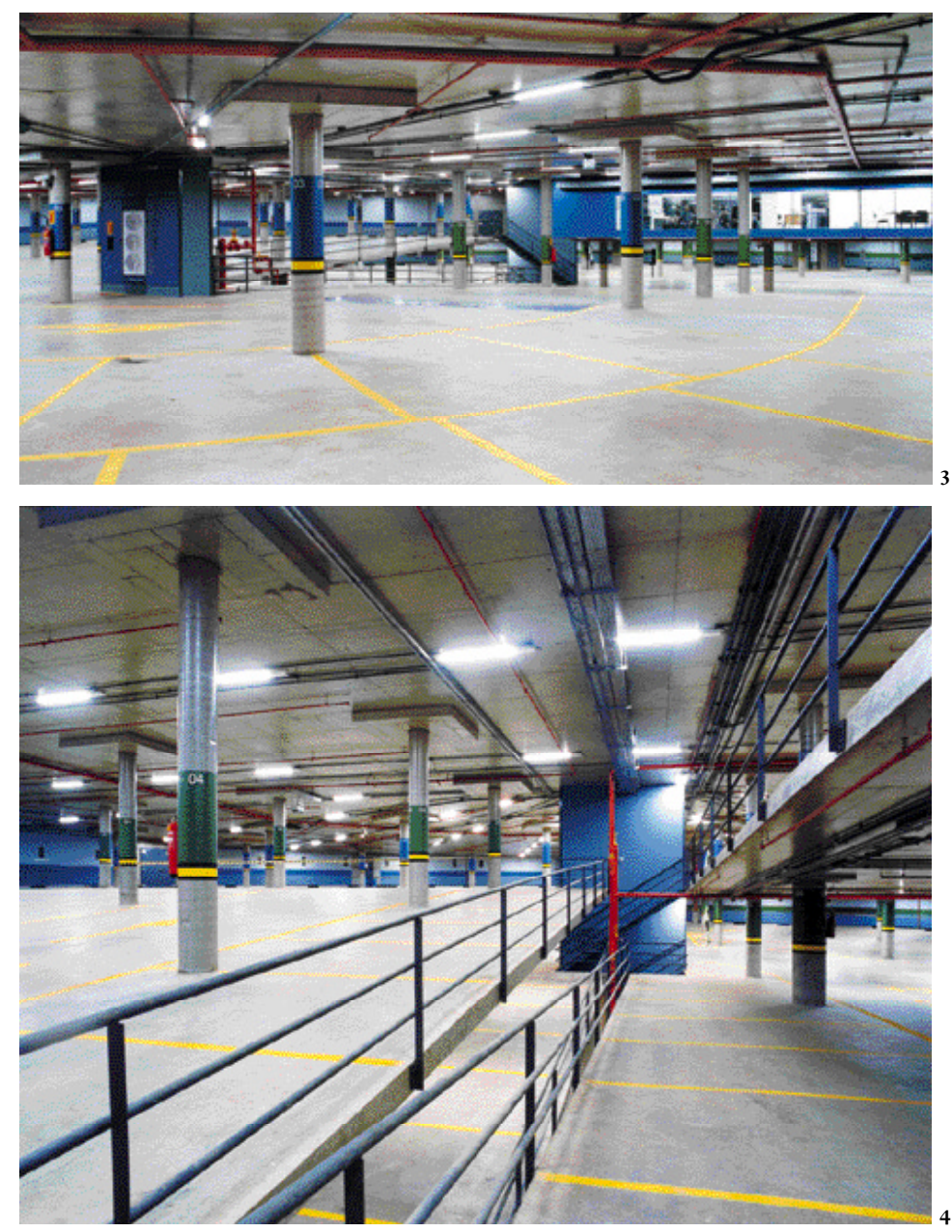

Estacionamientos subterráneos Trianon

Arquitectos Angelo Bucci, Fernando de Mello Franco,

Marta Moreira y Milton Braga

Colaboradora Keila Costa

Ubicación Av. Paulista, Sao Paulo, Brasil

Superficie construida $13.400 \mathrm{~m}^{2}$

Año proyecto 1996

Finalización de obra 1999

Fotografía Jorge Hirata

$\ln ^{2}$

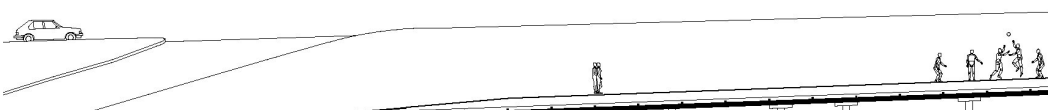

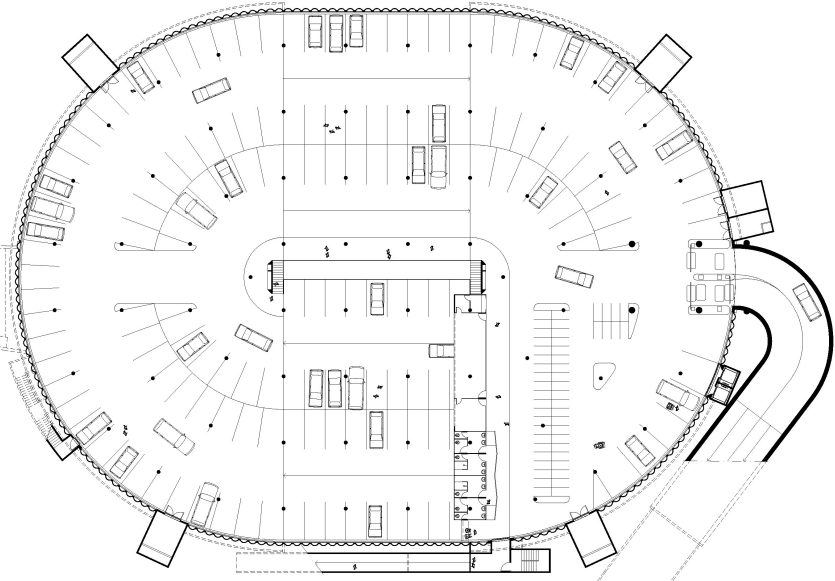

Planta nivel superior

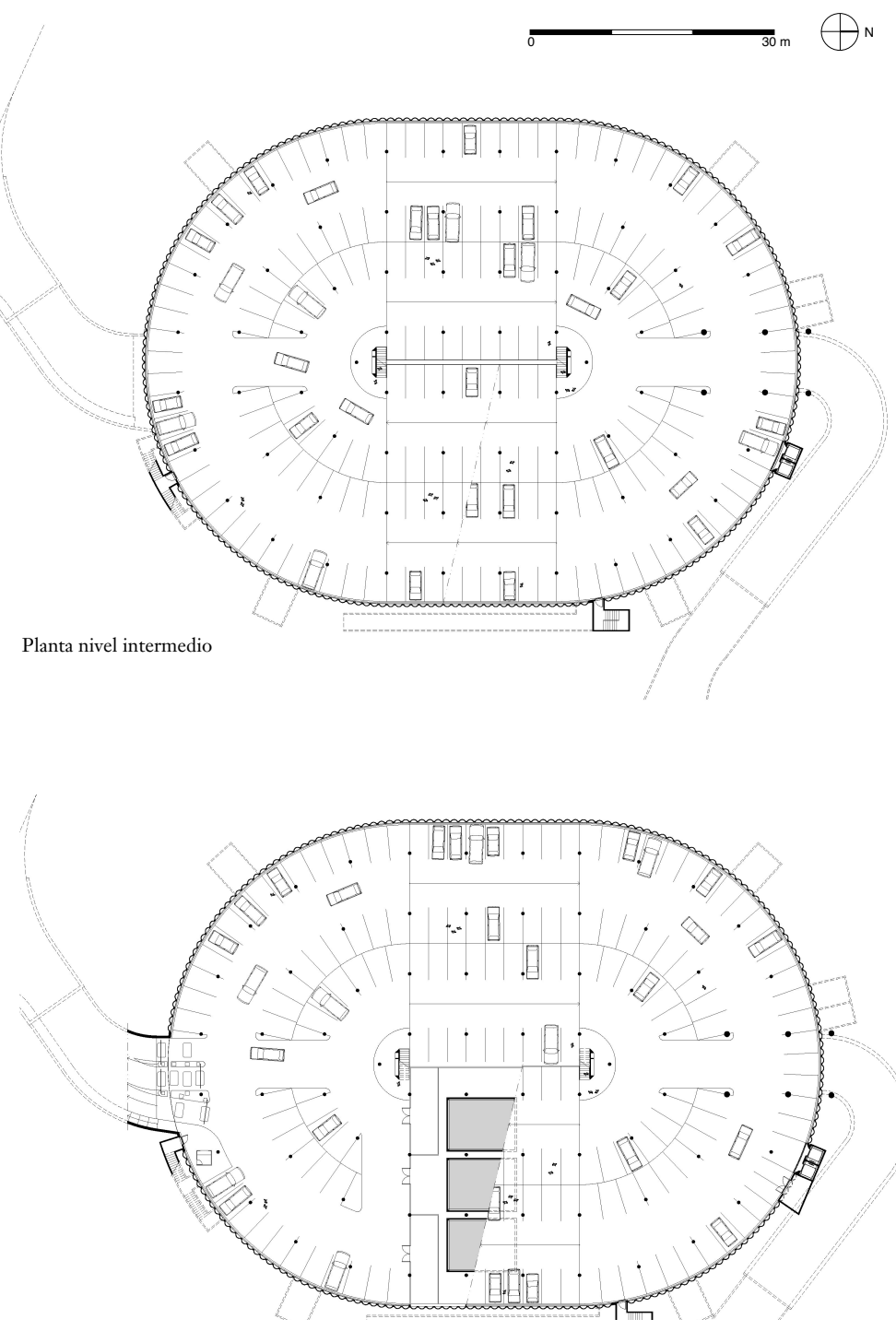

Planta nivel inferior

$-\infty$

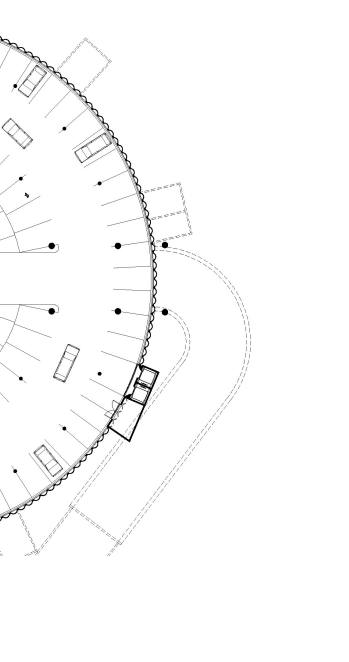

